\title{
Spindle cell oncocytoma: a new presentation of a rare disease
}

Nunes da Silva T.,Pereira B., Vara Luiz H., Velosa A., Matos AC., Portugal J. ${ }^{1}$ Nogueira J. ,Oliveira A. ${ }^{2}$

${ }^{1}$ Endocrinology department, Hospital Garcia de Orta, E.P.E.Almada Portugal ${ }^{2}$ Pathology department Hospital Garica de Orta E.P.E. Almada Portugal

\section{Introduction:}

Spindle cell oncocytoma (SCO) is a rare spindled to epithelioid, oncocityc, non-endocrine neoplasm of the adeno hypophysis with significant intra and supra-sellar infiltration. First described in 2002, it was codified as a separate entity in the 2007 and has been reported 18 times in the literature. Its clinical characteristics are similar to the much more prevalent pituitary macro-adenoma and has no reliable imagiologic criteria that allow its pre-surgical diagnosis. Despite a preliminary WHO grading of I, a recent review of 18 cases showed recurrent disease post-surgery in 7, with a median time of 3 years (range 1-13).

\section{Case description:}

i. Men, 65 years, sawman, without relevant past medical history

ii. Progressive visual bluring and episodic headaches since 12/2012
Emergency departement in 2/2013:

1. Oftalmologic evaluation : bitemporal hemianopsia 2. Head CT, $25 \mathrm{~mm}$ supra-selar nodule

\section{Admited to the neurosurgery unit:}

\begin{tabular}{lll}
\multicolumn{3}{c}{ Endocrine assessment before surgery } \\
Test & Value & Reference range \\
TSH & $0,46 \mathrm{mU} / \mathrm{L}$ & $0,1-4 \mathrm{mU} / \mathrm{L}$ \\
Total T4 & $1,8 \mathrm{ug} / \mathrm{dL}$ & $5,14-14,1 \mathrm{ug} / \mathrm{dL}$ \\
LH e FSH & $<0,1 / 0,4 \mathrm{UI} / \mathrm{L}$ & $1-7 / 1-12 \mathrm{UI} / \mathrm{L}$ \\
Total Testosterone & $<10 \mathrm{ng} / \mathrm{dL}$ & $180-750 \mathrm{ng} / \mathrm{dL}$ \\
IGF1 & $49,5 \mathrm{ng} / \mathrm{mL}$ & $75-212 \mathrm{ng} / \mathrm{mL}$ \\
Prolactin & $38,2 \mathrm{ng} / \mathrm{mL}$ & $1,6-20 \mathrm{ng} / \mathrm{mL}$ \\
ACTH & $<5 \mathrm{pg} / \mathrm{mL}$ & $9-50 \mathrm{pg} / \mathrm{mL}$ \\
Cortisol & $0,4 \mathrm{ug} / \mathrm{dL}$ & $7-25 \mathrm{ug} / \mathrm{dL}$
\end{tabular}

Right frontal craniotomy with partial removal of lesion
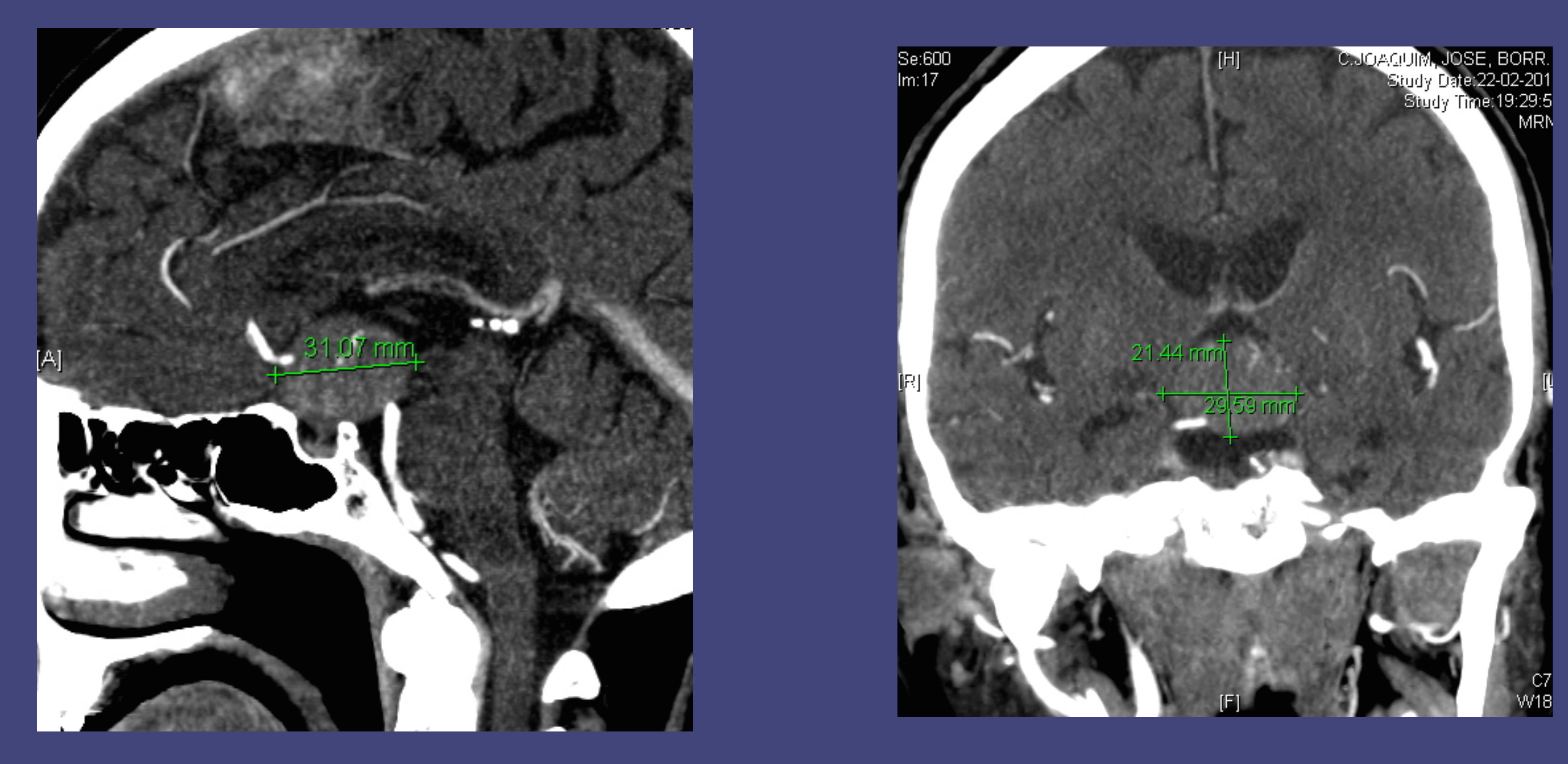

CT: supra-sellar tumor with $29 * 23 * 31 \mathrm{~mm}$ sharply demarcated from the pituitary. It also molded the optic chiasm (not shown)

\section{Highly vascular tumor with difficult cleavage plan from the pituitary}

\section{Spindle cell oncocytoma WHO grade I}

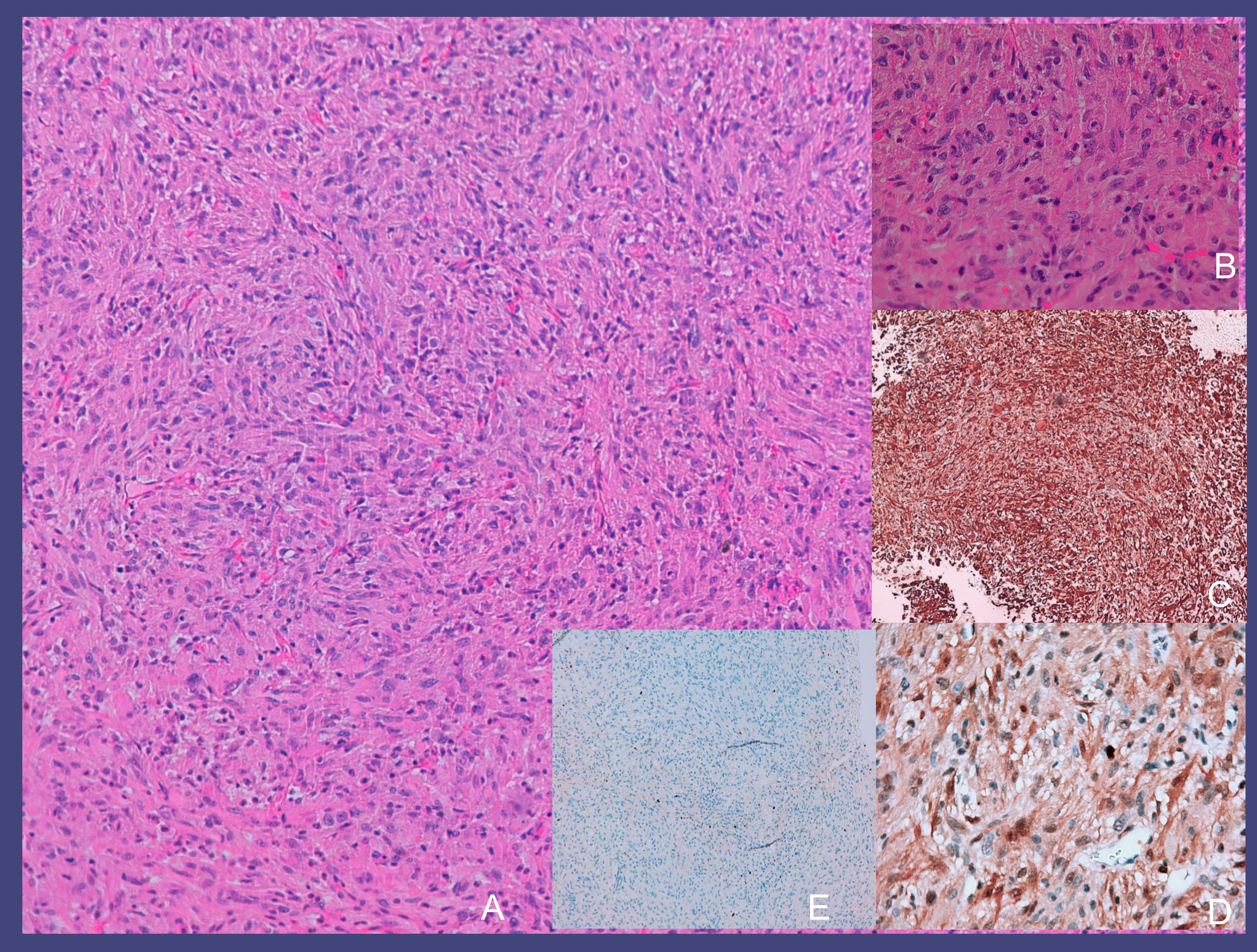

\section{Clinical follow-up}

Clinically after surgery: $\checkmark$ Central Diabetes Insípidus

$\checkmark$ Pan-hypopituitarism

$\checkmark$ Partial vision recovery
Hydrocortisone 20 mg/day Levotiroxyne 75 ug/day DDAVP 3x/day
Light microscopy with

H\&E showing interlacing fascicles of spindled to epithelioid cells with eosinophilic, variably oncocytic cytoplasm(A and B)

Immunohistochemistry: (+) immunostain for vimentin (C), S100 (D), focal EMA and (-) for GFAP and citokeratins. Ki $67<1 \%$ (E)

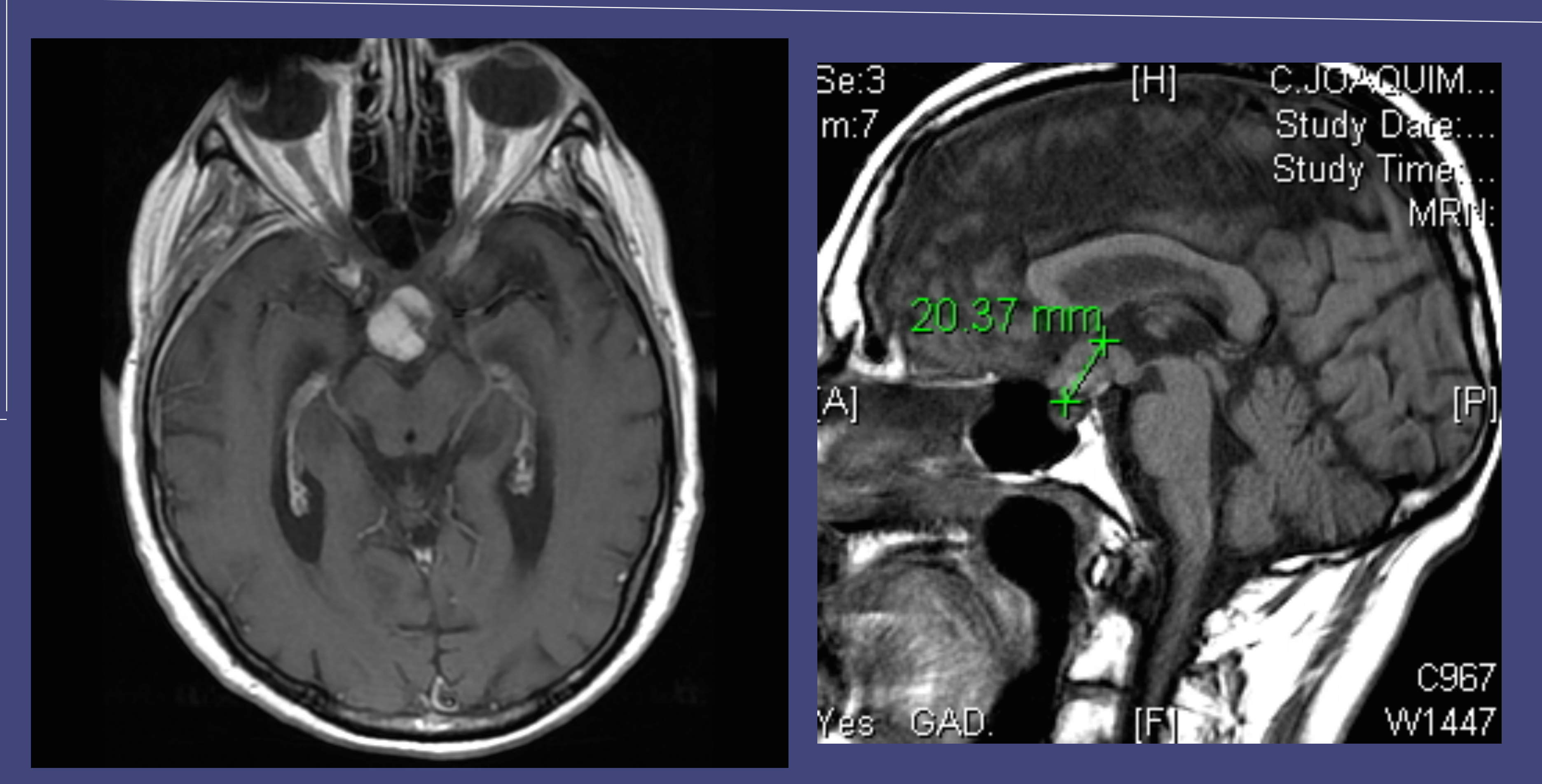

MRI 5 months latter: reduction in the tumor volume to $21 * 19 * 21 \mathrm{~mm}$ and a thin optic chiasm.

\section{Discussion:}

The authors present the first described SCO case with only supra selar presentation. This unique characteristic increases the difficulty of an already challenging preoperative diagnosis as it further shows that there are no clinical of radiologic signs that allow a differential diagnosis with the much more prevalent pituitary macro-adenoma. 